UDC 81'374

Submitted: 01.09.2020

LBC 81.054-03

Accepted: 24.12.2020

\title{
AXIOLOGICAL LINGUISTICS AND NATIONALLY ORIENTED LEXICOGRAPHY: EXPERIENCE OF INTERACTION (ON THE MATERIAL OF RUSSIAN-VIETNAMESE COMPARISONS) ${ }^{1}$
}

\author{
Aleksandr S. Mamontov \\ Pushkin State Russian Language Institute, Moscow, Russia \\ Vera V. Boguslavskaya \\ Pushkin State Russian Language Institute, Moscow, Russia \\ Ekaterina A. Budnik \\ Pushkin State Russian Language Institute, Moscow, Russia
}

Albertina G. Ratnikova

Pushkin State Russian Language Institute, Moscow, Russia

Trinh Thi Kim Ngoc

Vietnam Academy of Social Sciences, Hanoi, Vietnam

\begin{abstract}
The article touches upon the issues of theoretical and applied nature and reflects the essence of two adjacent linguistic scientific disciplines interaction, each studying the phenomenon of values that influence the formation of speech, behavioural and the communicative competence of a person. The authors consider this interaction future implementation in a unique lexicographic source designed to optimize the process of learning a language as a means of intercultural communication. Thus, authors are talking about a future dictionary, called "linguistic and cultura" and introducing the cultural component of the semantics of the units included in its vocabulary. The methodology for creating the concept of a dictionary is based on the analysis of the linguo-cognitive value system, where the concepts accentuate phenomenon, which allows one to explicate the specifics of the ethnic consciousness of a non-lingual culture representative. As examples of considering the semantic content, the authors offer the values as "love" and "labour", which are included in the primary system of values of the native speakers of the Russian language and culture. A strategy for the study of interaction of two related scientific disciplines was introduced: axiological linguistics and educational lexicography enable the creation of a new type of dictionary - a nationally oriented linguistic and cultural dictionary for the Vietnamese audience studying Russian as a means of intercultural communication. The article describes the experimental procedure, which is based on the theoretical and methodological framework. The analysis of the results obtained, revealed the specificity of the value orientations of the compared linguocultures. The research data relevance to educational lexicography theoretical and applied aspects is established. The contrasted research material, represented in the article, corresponds to the goals and objectives of the nationally oriented study.

Key words: axiological linguistics, nationally oriented lexicography, Russians, Vietnamese, value system, associative experiment, linguistic and cultural dictionary.

Citation. Mamontov A.S., Boguslavskaya V.V., Budnik E.A., Ratnikova A.G., Trinh Thi Kim Ngoc. Axiological Linguistics and Nationally Oriented Lexicography: Experience of Interaction (On the Material of Russian-Vietnamese Comparisons). Vestnik Volgogradskogo gosudarstvennogo universiteta. Seriya 2. Yazykoznanie [Science Journal of Volgograd State University. Linguistics], 2021, vol. 20, no. 1, pp. 101-113. (in Russian). DOI: https://doi.org/10.15688/jvolsu2.2021.1.8
\end{abstract}




\title{
АКСИОЛОГИЧЕСКАЯ ЛИНГВИСТИКА \\ И НАЦИОНАЛЬНО ОРИЕНТИРОВАННАЯ ЛЕКСИКОГРАФИЯ: ОПЫТ ВЗАИМОДЕЙСТВИЯ \\ (НА МАТЕРИАЛЕ РУССКО-ВЬЕТНАМСКИХ СОПОСТАВЛЕНИЙ) ${ }^{1}$
}

\author{
Александр Степанович Мамонтов \\ Государственный институт русского языка им. А.С. Пушкина, г. Москва, Россия \\ Вера Васильевна Богуславская \\ Государственный институт русского языка им. А.С. Пушкина, г. Москва, Россия
}

Екатерина Александровна Будник

Государственный институт русского языка им. А.С. Пушкина, г. Москва, Россия

\section{Альбертина Германовна Ратникова}

Государственный институт русского языка им. А.С. Пушкина, г. Москва, Россия

\section{Чинь Тхи Ким Нгок}

Вьетнамская академия общественных наук, г. Ханой, Вьетнам

\begin{abstract}
Аннотация. В статье затрагиваются вопросы теоретико-прикладного характера, отражающие вектор взаимодействия смежных лингвистических научных дисциплин, которые изучают феномен ценностей, оказывающих влияние на формирование речеповеденческой и коммуникативной компетенций человека. Утверждается, что в перспективе такое взаимодействие может быть воплощено в лексикографическом источнике особого типа, призванном оптимизировать обучение языку как средству межкультурной коммуникации через знакомство пользователей с культурным компонентом семантики единиц, входящих в его словник. Методология создания концепции словаря опирается на анализ системы ценностей как лингвокогнитивный и одновременно акцентуирующий феномен, позволяющий эксплицировать специфику этнического сознания представителя инолингвокультуры. В качестве примеров на фоне вьетнамской лингвокультуры охарактеризованы ценности «любовь» и «труд», входящие в базовую систему ценностей носителей русского языка и культуры. А.С. Мамонтовым предложена стратегия изучения взаимодействия двух смежных научных дисциплин: аксиологической лингвистики и учебной лексикографии при создании словаря нового типа. В.В. Богуславской разработана теоретико-методологическая база экспериментальной процедуры, описываемой в статье. Е.А. Будник на основе проведенного анализа полученных результатов выявлена специфика ценностных представлений сопоставляемых лингвокультур. А.Г. Ратниковой установлена релевантность полученных исследовательских данных поставленным перед авторами задачам в теоретико-прикладном аспекте. Чинь Тхи Ким Нгок обеспечена адекватность сопоставляемого материала целям и задачам данного национально ориентированного исследования.
\end{abstract}

Ключевые слова: аксиологическая лингвистика, национально ориентированная лексикография, русские, вьетнамцы, система ценностей, ассоциативный эксперимент, лингвострановедческий словарь.

Цитирование. Мамонтов А. С., Богуславская В. В., Будник Е. А., Ратникова А. Г., Чинь Тхи Ким Нгок. Аксиологическая лингвистика и национально ориентированная лексикография: опыт взаимодействия (на материале русско-вьетнамских сопоставлений) // Вестник Волгоградского государственного университета. Серия 2, Языкознание. - 2021. - Т. 20, № 1. - С. 101-113. - DOI: https://doi.org/10.15688/jvolsu2.2021.1.8

\section{Введение}

В современной парадигме научных исследований феномена «культура» понятие «ценность» занимает одно из ведущих мест.
Об этом ученые писали еще в середине XX в. (см., например: [Kluckhohn, Strodtbeck, 1961]). Мимо данного факта не могут пройти представители таких наук, как философия, культурология, психология, лингвистика, 
ибо, по их общему мнению, основу любого культурного кода составляют именно ценности [Матвеев, 2006]. Думается, в данном контексте нет необходимости говорить о масштабности взаимодействия человека и объективной действительности. Оно реализуется как в использовании человеком благ, созданных природой, так и в его деятельности, направленной на преобразование природы, где своего рода локомотивом выступает коллективный труд, обеспечивающий ее освоение. В этом контексте особую роль для филолога играет понимание механизмов, обеспечивающих многогранность отношений между био- и ноосферой в ценностном аспекте, с точки зрения социальной значимости, а главное - отражение данных отношений в языковых единицах, что является содержанием такой относительно новой научной дисциплины, как аксиологическая лингвистика [Карасик, 2002], и только зарождающейся дисциплины под названием «национально ориентированная учебная лексикография» [Цэдэндоржийн, 2015; Мамонтов, Цэдэндоржийн, Богуславская, 2019]. При этом, на наш взгляд, наиболее продуктивной следует считать сентенцию, согласно которой именно ценности представляют собой основу любой лингвокультуры. Следовательно, овладение любым без исключения языком как средством межкультурной коммуникации требует от инофона обязательного овладения сопряженной с языком системой ценностей, составляющей часть содержания изучаемой им культуры.

Представителю инолингвокультуры, изучающему чужой язык как средство коммуникации с его носителями, невозможно избежать объективных трудностей, возникающих в ходе учебного процесса. Помочь преодолеть некоторые из них может национально ориентированная лингвострановедческая учебная лексикография, призванная обеспечить создание словаря нового типа, учитывающего национальную специфику родной культуры адресата, что позитивных образом влияет на эффективность учебного процесса. Одновременно национально ориентированная лингвострановедческая учебная лексикография решает задачи описания взаимоотношений, сложившихся между языком и культурой, на- шедших отражение в словаре, учитывающем родную культуру адресата [Мамонтов, Цэдэндоржийн, Богуславская, 2019, с. 76].

Наряду с понятием «ценность» в научном обиходе представлено понятие «ценностная ориентация личности» (далее - ЦО), введенное социологами У. Томасом и Ф. Знанецким в 20-е гг. прошлого века (подробно об этом см.: [Баразгова, 1997]). Они рассматривали ЦО в качестве установки личности, которую отличают социальная детерминированность и регулятивность. Последняя в свою очередь способна влиять на поведение личности, позволяя говорить о том, что именно ценностные предпочтения, структурируемые по-своему каждым членом социальной группы, в значительной степени определяют характер формирующейся в социуме системы ЦО. Однако, по мнению исследователей, у людей, проживающих в схожих условиях, вырабатывается система ЦО, типичная для всего коллектива.

В целях экспликации потенциала национально ориентированной лексикографии нами была предпринята попытка сопоставительного анализа содержания русских и вьетнамских ценностей, что имеет определенное значение и теоретическое, и прикладное, способствуя повышению уровня эффективности обучения русскому языку как иностранному.

\section{Аксиологическая лингвистика: основные понятия и подходы}

В аксиологической лингвистике, или лингвоаксиологии, понятия «ценность» и «оценка» выступают в качестве ключевых. Они отсылают нас к проблемам, связанным с языковым сознанием [Карасик, 2002; Синячкин 2009; Уфимцева, 2015] и языком как системно-структурным образованием [Верещагин, Костомаров, 1990; Иванова, 2004], в том числе на уровне лексики [Богданова, 2017; Вежбицкая, 2001; Гладкова, 2010; Wierzbicka, 2003; Goddard, Wierzbicka, 2014] и фразеологии [Фразеология в контексте культуры, 1999], на уровне грамматики [Богданова, 2018; Козлова, 2018, Meaning and Universal Grammar..., 2002], а также вызывают исследовательский интерес в аспекте теории коммуникации [Леонтович, 2005; Ларина, Озюменко, 
2017; Wierzbicka, 2003; Kecskes, 2014; Larina, Ozyumenko, Kurteš, 2017; Leech, 2014].

Импульсом для развития данного направления в лингвистике, по нашему мнению, явились идеи о природе и месте ценностей, нашедшие свое отражение в трудах Н.Д. Арутюновой и Е.М. Вольф. В целях наглядности разнообразие исследовательских векторов аксиологической лингвистики представим следующим образом:

- изучение оценки как категории, связанной с философией, эстетикой, логикой, этикой и одновременное описание ее в общетеоретическом плане, формирующее представления как о разных видах оценочных значений, так и о способах их реализации [Арутюнова, 1984; 1988; Вольф, 1985];

- изучение системы ценностей в аспекте ее связи с разными типами личности [Карасик, 2005];

- изучение базовых оценочных преференций с позиции взаимодействия культуры и языка [Бартминьский, 2005; Березович, 2007];

- исследование компонентов русской языковой картины мира на фоне специфики национального сознания как отражения системы ценностных координат представителей русской лингвокультуры [Зализняк Анна А., Левонтина, Шмелев, 2012];

- изучение фразеологического фонда русской лингвокультуры, способного сигнализировать об особенностях ценностного и оценочного компонентов семантики фразеологизма в аспекте лингвокультурологии [Телия, 1996];

- изучение истории понятий и природы ценностей в аспекте лингвоаксиологии [Живов, 2009];

- исследование оценок и моделирование оценочной структуры дискурса, выполняемые, как правило, на материале дискурсов медиаполитического жанра (обусловленные тем, что именно указанные типы могут быть отмечены особым ценностным потенциалом воздействия на реципиента [Марьянчик, 2013].

Итак, в настоящее время можно с уверенностью говорить об аксиологической лингвистике как о динамично развивающейся научной дисциплине, активно взаимодействующей с близкими ей лингвистическими направлениями и предлагающей при этом как свой исследовательский аппарат, так и заимствованный (в том числе из философии и социологии) [Этносемиометрия..., 2008].

Вместе с тем терминологический аппарат и предлагаемая исследовательская методология аксиологической лингвистики пока еще далеки от стадии окончательного оформления. Например, многие ее термины«аксиологическая горизонталь», «аксиологическая вертикаль», «аксиосфера» и др. - еще не вполне закрепились в лингвистической литературе и допускают неоднозначную трактовку. Это касается, в частности, таких терминов, как «оценка» и «оценочность» [Сальникова, 2014, с. 10-11].

Обращает на себя внимание то, что, будучи лингвистической категорией, оценочность, базируясь на речемыслительной операции оценки, отражает картину мира. В данной ипостаси она находится во взаимодействии с бытующими в языковом сообществе представлениями о ценности объекта и социально маркируется, предопределяя то, что индивидуум со всеми особенностями его, во многом непредсказуемого бытия, но во взаимодействии с социумом и объективной действительностью предстает субъектом и объектом оценки одновременно [Маркелова, 2007].

Комментария требует, на наш взгляд, тот факт, что понятия «оценочность» и «оценка» нередко выступают в роли синонимов (см., например: [Зализняк Анна А., Левонтина, Шмелев, 2012]). Это представляется не совсем корректным, ибо в научной практике существует опыт их разграничения по линии «действие» («оценка») и «свойство» («оценочность»).

Продуктивной представляется точка зрения И.А. Стернина, который предлагает выделять так называемую «коммуникативную оценочность», которая, по мнению лингвиста, является неким феноменом «коммуникативного поведения», характеризующегося стремлением к оценке реальной действительности с позиции языка, и где значимую роль играют, в частности, степень категоричности высказываемых оценок, степень оценочности формального общения наряду с повседневным, а также степень допустимости негативных оценок в разговоре и т. Д. [Стернин, 2003, с. 11]. Все это дает основания считать термин «оценочность» 
релевантным для использования в том числе и в области коммуникативистики.

В научной литературе находит отражение узкое и широкое понимание феномена оценки. При узком понимании акцент делается на характеристике предметно-признаковых особенностей какого-либо объекта, факта или ситуации в соответствии с суждением «хорошо - плохо», при широком понимании - на характеристиках, соотносимых с суждениями «истинно - ложно», «важно - неважно». Как отмечает В.В. Лопатин, при этом на передний план выходит субъект речи: именно с его позиций оценочные компоненты (квалификативные компоненты языка) корректируют содержание высказываний [Лопатин, 2007, c. 536-537].

Заслуживает внимания и тот факт, что связанное с речепорождением взаимодействие оценок и ценностей, весьма непростое на наш взгляд, эксплицируется через категорию аксиологичности, функциональную по сути и определяемую в качестве некой способности к моделированию, воспроизводству и т. д. как ценностей, так и антиценностей языковой картины мира, существующей в сознании и продуциента, и реципиента текстокоммуникации (об этом см.: [Марьянчик, 2013, с. 248]).

В то же время нельзя не отметить наблюдаемый сегодня интенсивный контакт аксиологической лингвистики с рядом научных дисциплин и направлений, таких как лингвокультурология, межкультурная коммуникация, этнопсихолингвистика, национально ориентированная учебная лексикография, о которой речь идет в настоящей статье. Интенсивность этого взаимодействия обусловлена все нарастающим интересом к заложенной в языке категории ценности и ее разнообразных проявлениях.

С позиций аксиологической лингвистики языковое сознание следует рассматривать в качестве одного из видов обыденного сознания, являющегося своего рода механизмом управления речевой деятельностью. Проводимое нами исследование языкового (обыденного) сознания разных лингвокультур путем сопоставления соответствующих образов мира представляется особенно значимым на современном этапе развития человечества, в эпоху расширения и углубления кросс-культурных контактов, способных отражать специфику сопоставляемых лингвокультур. Необходимо подчеркнуть, что исследования, подобные нашему, целесообразно начинать с рассмотрения ценностного отношения к тому или иному предмету или явлению как к феномену культуры. Здесь, как отмечалось выше, важную роль играет так называемая лингвострановедческая лексикография, одной из основных задач которой сегодня является разработка концепции учебного словаря нового типа - национально ориентированного лингвострановедческого словаря, адресованного иностранной аудитории, овладевающей русским языком как средством межкультурной коммуникации.

В статье представлены некоторые промежуточные результаты разработки такого словаря, ориентированного на вьетнамских реципиентов. Проведена систематизация лексикографических данных и данных ассоциативного эксперимента, которая нацелена на верификацию гипотезы, заключающейся в том, что национально ориентированные лингвострановедческие учебные словари, в том числе русского языка, способны обеспечить гораздо большую эффективность процесса овладения языком как средством межкультурного общения.

\section{Ассоциативный эксперимент: процедура проведения и результаты}

Для проведения эксперимента нами были выбраны ассоциативные поля (далее - АП) «любовь» и «труд», являющиеся наиболее показательными с точки зрения тех исследовательских задач, которые мы перед собой ставили. Для определения содержания этих АП в русской лингвокультуре использованы данные «Русского ассоциативного словаря» (далее - РАС), поскольку именно РАС как словарь-тезаурус дает наиболее всестороннюю и полную картину вербальной памяти и языкового сознания «среднего русского». Данные о наполнении АП «любовь» и «труд» во вьетнамской лингвокультуре получены в результате ассоциативных экспериментов, проводимых в Государственном институте русского языка им. А.С. Пушкина, Российском университете дружбы народов, Московском педагогическом государственном университе- 
те в период с 2010 по 2020 год. В эксперименте принимали участие преимущественно студенты филологического профиля, общим количеством 100 человек (женского и мужского пола). В статье рассматриваются слова-ассоциаты в количестве не менее двух.

АП эксплицируют особенности речевого поведения в созданной экспериментальным путем ситуации: дается вербальная реакция испытуемых на вербальный стимул, отражая, таким образом, содержание фоновых знаний. Последние, соотносимые со словами-реакциями, выступают как некое вербализованное, имплицитное представление о предметах, явлениях, в той или иной степени связанных со словом-стимулом. Следовательно, есть все основания сделать вывод о том, что АП через слова-реакции отражают конгломерат как предметов, так и явлений, образующих своего рода «культурный контекст» феномена, подвергшегося экспериментальному анализу.

В предлагаемом нами эксперименте исследование ассоциативных полей номинативных единиц, обозначающих ценности, обеспечивает возможность проникновения вглубь содержания последних, а методика сопоставления полей, например, ценностей «любовь» и «tinh yêu» не только позволяет получить представление об объеме знаний, обусловленных содержанием конкретных ценностей, но и способствует выявлению специфики компонентов фоновых знаний носителей конкретных языков и культур, восполняя таким образом нередко существующие лексикографические пробелы.

\section{Ценность «Любовь»}

Содержание ЦО «Любовь» проявляется в семантике слова, ее номинирующего.

В «Большом толковом словаре русского языка» С.А. Кузнецова зафиксировано четыре значения слова любовь:

1) чувство глубокой привязанности к кому-л., чему-л.;

2) чувство горячей сердечной склонности, влечения к лицу другого пола;

3) о человеке, внушающем такое чувство;

4) внутреннее стремление, влечение, склонность, тяготение к чему-л. (Кузнецов, c. 453$)$.
В словаре «Словаре вьетнамского языка» Хоанг Фе слово tình yêu (любовь) зафиксировано в двух значениях:

1) Tình cảm nồng nhiệt làm cho gắn bó mật thiết và có trách nhiệm với người, với vật. Tình yêu quê huơng (Сердечное чувство, вызывающее интимную и ответственную привязанность к людям и предметам);

2) Tình cảm yêu thương giữa nam và nữ. Tình yêu son sắt, thủy chung (Глубокое эмоциональное влечение мужчины и женщины друг к другу) (Hoàng Phê, tr. 601).

\section{Ценность «Любовь» \\ в русской лингвокультуре}

ЛЮБОВЬ: с первого взгляда - 9; до гроба - 8; чувства -5 ; зла, счастье - 3 ; безответная, горе, и голуби, к женщине, ненависть, платоническая, пришла, радость, разлука, страстная, Яровая - 2 (РАС, т. 2, с. 511).

\section{Ценность «Тїn уе̂и (Любовь)» \\ во вьетнамской лингвокультуре}

TìNH YÊU: счастье - 10; дружба - 7; брак - 6; верная -5; красивая, поцелуй, мать -4; глубокая, романтичная, сопереживание и согласие 2 сердец, мужчина и женщина, жизнь -2 .

\section{Интерпретачия полученных данных}

В языковом сознании вьетнамцев tìn hyêu (любовь) вызывает в первую очередь реакцию счастье - 10. Далее следуют дружба - 7 и брак - 6. Считаем, это связано с тем, что любовь - это то, что порождает брак и способствует созданию семьи - самой большой ценности для представителей вьетнамской лингвокультуры. Вызывает интерес и то, что в данной лингвокультуре релевантна связь любви с дружбой, на это указывает соответствующий ассоциат. В русском ассоциативном ряду подобная связь не зафиксирована. Можно предположить, что поскольку в русской семье традиционно более сильны патерналистские отношения, в целом несвойственные понятию «дружба», основанному на принципах равенства.

В русском ассоциативном ряду, в отличие от вьетнамского, фиксируется значительное количество ассоциатов с негативной оцен- 
Аксиологическая лингвистика и национально ориентированная лексикография: опыт взаимодействия

кой: зла - 3; безответная, горе, ненависть, разлука - 2. Представляется, что поскольку ценность «Любовь» в русском лингвокультурном пространстве, в отличие от вьетнамского, традиционно связывается с понятием «жертвенность», с более оптимистической сутью самой ценности, подсознание русского как бы «запрограммировано» на преодоление тех негативных моментов, с которыми человек вынужден считаться или уже считается.

Для русских респондентов, в отличие от вьетнамских, ценность «Любовь» в языковом сознании не связана с понятием «брак» в силу тех социокультурных причин, о которых упоминалось выше. Заслуживает внимания и тот факт, что для представителей вьетнамского социума значительную роль играет такое понятие, как верность (ср.: sự chung thủy (верность) в качестве ассоциата упомянуто 5 раз): общественное поведение отвергает измену во всех ее проявлениях.

Можно предположить определенное влияние на сознание представителей русской лингвокультуры устойчивых языковых выражений любовь с первого взгляда, любовь до гроба, любовь зла; названий популярных кино- и драматургических произведений: кинофильм «Любовь и голуби»; пьеса «Любовь Яровая». Согласно нашим наблюдениям, уровень прецедентности в коммуникативном поведении представителей русской лингвокультуры выше, чем во вьетнамской, что, как думается, связано с более высокой степенью участия разных видов СМИ в формировании как индивидуального, так и общественного сознания.

\section{Ценность «Труд»}

Содержание ЦО «Труд» проявляется в семантике слова, ее номинирующего.

В «Большом толковом словаре русского языка» С.А. Кузнецова зафиксировано пять значений слова труд:

1) целесообразная деятельность человека, направленная на создание с помощью орудий производства материальных и духовных ценностей;

2) работа, занятие;

3) усилие, направленное к достижению чего-н.;
4) результат деятельности, работы; произведение;

5) предмет школьного образования. Обучение навыкам какой-л. профессиональной, хозяйственной деятельности (Кузнецов, c. 922).

В словаре «Словаре вьетнамского языка» Хоанг Фе слово lao động (труд) зафиксировано в четырех значениях:

1) Hoạt động có mục đích của con người nhằm tạo ra các loại sản phẩm vật chất và tinh thần cho xã hội. Lao động chân tay. Lao động nghệ thuạt. Súc lao động (Целесообразная деятельность человека, направленная на создание материальных и духовных ценностей для общества);

2) Việc làm lao động cụ thể, nói về mặt tạo ra sản phẩm. Trả luơng theo lao động. Năng suất lao động (Конкретная работа, направленная на создание продуктов);

3) Sức người bỏ ra trong việc làm lao động cụ thể. Tiết kiệm lao động. Hao phí lao động (Tpyдовые ресурсы, затраченные на конкретную производительную деятельность);

4) Người làm lao động (nói về lao động chân tay, thường là trong sản xuất nông nghiệp). Nhà có hai lao động chính (Рабочая сила, о ручном труде, обычно в сельском хозяйстве) (Hoàng Phê, trang 401).

\section{Ценность «Труд» \\ в русской лингвокультуре}

ТРУД: работа - 53; тяжелый - 45; мир 14 ; облагораживает, ударный - 13 ; лень, май 12 ; мир, май; на благо - 11; непосильный, полезный -9 ; напрасный -8 ; адский -7 ; дело, каторжный, легкий, лопата, радость, упорный - 6; газета, добросовестный, обязанность, отдых, честный - 5; бесполезный, людей, мирный, молоток, пруд, работать, радостный, ратный, усталость, физический, человека - 4; безделье, бесплатный, благо, великий, впустую, деятельность, доблестный, земля, коммунистический, на благо Родины, необходим, общественный, подневольный, производительный, рабочий, руки, свободный, созидательный, умственный, урок, хорошо - 3; бескорыстный, благородный, всему голова, деньги, жизни, завод, земледельца, и мир, лодырь, лозунг, надо, наш, нелегкий, обезьяна, 
общественно полезный, полезен, посильный, почетный, праведный, пустой, рабский, создал человека, социалистический, терпение, «Труд», труп, тяжкий, учителя - 2.

\section{Ценность «Lao động» (Труд)}

во вьетнамской лингвокультуре

LAO ĐỘNG: работа - việc làm - 50; жить - trực tiếp - 40; уставать - mệt, вместе cùng với nhau - 20; жизнь - cuộc sống - 12; думать - nghĩ, тяжело - nặng, хорошо - tốt - 10; деятельность - hoạt động, эффективно - hiệu quả - 7; стабильно - đều đặn, всегда - luôn luôn -5 ; все - mọi thứ, цель - мục tiêu, quyền lực -2 .

\section{Интерпретация полученных данных}

Представляется значимым то, что в русском ассоциативном ряду значительное количество слов-ассоциатов с негативной окраской (тяжелый, лень, непосильныій, адский, каторжный) находятся не на периферии языкового сознания. Данный факт следует рассматривать с точки зрения традиционного отношения русских к труду как к чему-то онтологически всегда нелегкому в силу природно-климатических условий, территориальных особенностей, исторической судьбы и пр. (тяжсельй - 45), но необходимому, а посему особо значимому (облагораживает - 13; полезныци-9).

Для вьетнамцев ценность «труд» в первую очередь неразрывно связана с понятием «жить» (trực tiếp (жить) в качестве ассоциата упомянуто 40 раз), что ни коим образом не сигнализирует о степени легкости труда в данном социуме (ср.: слово nặng (тяжело) упомянуто как ассоциат 10 раз). Однако степень «борьбы за выживание» в процессе труда в природноклиматических условиях, где возможен сбор урожая три-четыре раза в год, объективно ниже, чем в России, что и отражается в языковом сознании представителей тропической страны. Если для русских ценность «труд»это чаще всего борьба с природными стихиями и нередко с самим собой, в условиях монотонной, скучной работы, провоцирующей такое качество, как лень (соответствующий ассоциат упомянут 12 раз), в ситуации психологическо- го комфорта вполне преодолеваемое, о чем свидетельствует наличие в АП слова ударный, то для представителей вьетнамского социума данная ценность более гармонична как естественная часть человеческого бытия.

Можно также констатировать в русском языковом сознании, по сравнению с вьетнамским, бо́льшую степень влияния прецедентности как части идеологической составляющей культуры недавнего прошлого: мир - 14; yдарный - 13; мир, май; на благо - 11. Во вьетнамском лингвосознании, во многом сохраняющем подобную идеологию: cuộc sống - «жизнь»-12; hiệu quả - «эффективно» - 7; mọ thú - «все», мис tіеи - «цель»-2.

\section{Выводы}

Итак, теоретические положения работ, выполненных в русле аксиологической лингвистики и выявляющих национальнокультурную специфику семантики, и результаты сопоставительных экспериментальных процедур, направленных на исследование ассоциативных полей, могут быть положены в основу востребованных на современном этапе национально ориентированных лингвострановедческих учебных словарей, знакомящих пользователей с культурным компонентом семантики единиц, входящих в их словник. В ходе составления такого учебного словаря, адресованного вьетнамской аудитории, изучающей русский язык как средство межкультурного общения, проведены сопоставительные эксперименты, демонстрирующие значимость эмпирического анализа общечеловеческих ценностей «любовь» и «труд» для описания особенностей языкового сознания этноса. Оно, будучи составной частью национального общественного сознания, отражено в семантике языковых единиц. Именно его верифицированное и по возможности адекватное отображение должно быть представлено в структуре современных национально ориентированных учебных лингвострановедческих словарей. Такой подход позволит избежать интерференции ценностей, затрудняющей усвоение иностранного языка как одной из форм межкультурной коммуникации и препятствующей эффективному диалогу культур. 


\section{ПРИМЕЧАНИЕ}

${ }^{1}$ Работа выполнена при поддержке гранта РФФИ (научный проект № 20-512-92001 «Разработка концепции лингвострановедческого национально ориентированного учебного словаря русского языка для вьетнамских граждан»).

The research is funded by Russian Foundation for Basic Research (project No 20-512-92001 "Framework Development of Linguistic-and-Cultural Nationally Focused Learner's Dictionary of the Russian Language for Vietnamese Citizens").

\section{СПИСОК ЛИТЕРАТУРЫ}

Арутюнова Н. Д., 1984. Аксиология в единицах языка и речи // Проблемы структурной лингвистики. 1982. М. : Наука. С. 5-23.

Арутюнова Н. Д., 1988. Типы языковых значений. Оценка. Событие. Факт. М. : Наука. 341 с.

Баразгова Е. С., 1997. Американская социология : Традиции и современность. Екатеринбург : Деловая кн. ; Бишкек : Одиссей. 173 с.

Бартминьский Е., 2005. Языковой образ мира: очерки по этнолингвистике. М. : Индрик. $527 \mathrm{c}$

Березович Е. Л., 2007. Язык и традиционная культура: этнолингвистические исследования. М. : Индрик. 599 с.

Богданова Л. И., 2017. Оценки и ценности в зеркале словарей русского языка // Вестник РУДН. Серия: Лингвистика. Т. 21, № 4. С. 729-748.

Богданова Л. И., 2018. Оценочные смыслы в русской грамматике // Вестник РУДН. Серия: Лингвистика. Т. 22, № 4. С. 844-873.

Вежбицкая А., 2001. Понимание культуры через посредство ключевых слов. М. : Яз. слав. культуры. 288 с.

Верещагин Е. М., Костомаров В. Г., 1990. Язык и культура. Лингвострановедение в преподавании русского языка как иностранного. М. : Рус. яз. 246 c.

Вольф Е. М., 1985. Функциональная семантика оценки. М. : Наука. 228 с.

Гладкова А. Н., 2010. Русская культурная семантика : Эмоции, ценности, жизненные установки. М. : Яз. слав. культур. 295 с.

Живов В. М., 2009. История понятий, история культуры, история общества // Очерки исторической семантики русского языка раннего Нового времени / под ред. В. М. Живова. М. : Яз. слав. культур. С. 5-26.

Зализняк Анна А., Левонтина И. Б., Шмелев А. Д., 2012. Константы и переменные русской языковой картины мира. М. : Яз. слав. культур. 696 c.
Иванова С. В., 2004. Лингвокультурология и лингвокогнитология: сопряжение парадигм. Уфа : РИО БашГУ. 152 с

Карасик В. И., 2002. Язык социального статуса. М. : Гнозис. 333 с.

Карасик В. И., 2005. Лингвокультурный типаж «русский интеллигент» // Аксиологическая лингвистика: лингвокультурные типажи : сб. науч. тр. / под ред. В. И. Карасика. Волгоград : Парадигма. С. 25-61.

Козлова Л. А., 2018. Этнокультурный потенциал залоговых форм и его дискурсная актуализация // Вестник РУДН. Серия: Лингвистика. Т. 22, № 4. С. 874-894.

Ларина Т. В., Озюменко, В. И., 2017. Свобода личности как конституирующий компонент английского дискурса // Известия Южного федерального университета. Филологические науки. № 2. С. 160-172.

Леонтович О. А., 2005. Русские и американцы: парадоксы межкультурной коммуникации. М. : Гнозис. 344 с.

Лопатин В. В., 2007. Оценка как объект грамматики // Многогранное русское слово : Избранные статьи по русскому языку / под ред. О. Е. Ивановой. М. : Азбуковник. С. 536-542.

Мамонтов А. С., Цэдэндоржийн Э., Богуславская В. В., 2019. Лингвострановедческий учебный словарь для монгольских граждан: специфика представления материала // Вестник Волгоградского государственного университета. Серия 2, Языкознание. Т. 18, № 1. C. 74-85. DOI: https://doi.org/10.15688/ jvolsu2.2019.1.6.

Маркелова Т. В., 2007. Аксиологичность как имманентное свойство газетно-публицистического текста // Язык и стиль современных СМИ : межвуз. сб. науч. тр. Всерос. конф., посвящ. 80-летию проф. Н. С. Валгиной. М. : МГУП. C. 231-238.

Марьянчик В. А., 2013. Аксиологичность и оценочность медиа-политического текста. М. : Либроком. 272 с.

Матвеев П. Е., 2006. Этика. Основы общей теории морали. Владимир : Изд-во Владим. гос. ун-та. 81 с.

Сальникова Ю. А., 2014. Аксиологические аспекты медиадискурса. Биробиджан : Изд. центр ФБГОУ ВПО «ПГУ им. Шолом-Алейхема». $157 \mathrm{c}$.

Синячкин В. П., 2009. Формы существования общечеловеческих ценностей в русской культуре // Вестник Чувашского государственного педагогического университета. № 10-2. С. 273-288.

Стернин И. А., 2003. К разработке модели контрастивного описания национального комму- 
никативного поведения // Аксиологическая проблематика: проблемы коммуникативного поведения : сб. науч. тр. под ред. В. И. Карасика, Н. А. Красавского. Волгоград : Перемена. С. 5-15.

Телия В. Н., 1996. Русская фразеология. Семантический, прагматический и лингвокультурологический аспекты. М. : Яз. рус. культуры. $288 \mathrm{c}$.

Уфимцева Н. В., 2015. Ядро языкового сознания как отражение системности образа мира // Язык в пространстве речевых культур. К 80-летию Е.В. Гольдина. М. ; Саратов : Наука образования. С. 335-342.

Фразеология в контексте культуры, 1999 : сб. ст. / отв. ред. В. Н. Телия. М. : Яз. рус. культуры. $333 \mathrm{c.}$

Цэдэндоржийн Э., 2015. Язык и культура: основы национально ориентированной лексикографии (с позиции носителя монгольского языка). М. : Гос. ИРЯ им. А.С. Пушкина. 200 с.

Этносемиометрия ценностных смыслов, 2008 : коллектив. моногр. Иркутск : ИГЛУ. 529 с.

Meaning and Universal Grammar: Theory and Empirical Findings. In 2 Vols., 2002 / ed. by C. Goddard, A. Wierzbicka. Amsterdam : John Benjamins. 2 vols.

Goddard C., Wierzbicka A., 2014. Words and Meanings: Lexical Semantics Across Domains, Languages, and Cultures. Oxford : Oxford University Press. 316 p.

Kecskes I., 2014. Intercultural Pragmatics. Oxford : Oxford University Press. 277 p.

Kluckhohn F., Strodtbeck F. L., 1961. Variations in Value Orientations. Connecticut : Greenwood Press. 437 p.

Larina T. V., Ozyumenko V. I., Kurteš S., 2017. I-Identity vs We-Identity in Language and Discourse // Anglo-Slavonic Perspectives Lodz Papers in Pragmatics. Vol. 13, iss. 1. P. 109-128.

Leech G., 2014. The Pragmatics of Politeness. Oxford : Oxford University Press. 369 p.

Wierzbicka A., 2003. Cross-Cultural Pragmatics. $2^{\text {nd }}$ ed. Berlin, N. Y. : Mouton de Gruyter. $502 \mathrm{p}$.

\section{ИСТОЧНИКИ И СЛОВАРИ}

Кузнецов - Кузнецов С. А. Новый большой толковый словарь русского языка. СПб. : Норинт, 2000. 1536 c.

$P A C-$ Русский ассоциативный словарь. В 2 т. / под ред. Ю. Н. Караулова. М. : АСТ : Астрель, 2002. 2 т.

Hoàng Phê - Hoàng Phê. Từ điển Tiếng Việt. Viện Ngôn ngữ học : NXB Đà Nẵng, 2003. 1222 tr.

\section{REFERENCES}

Arutyunova N.D., 1984. Aksiologiya v edinicakh yazyka i rechi [Axiology in the Mechanisms of Life and Language]. Problemy strukturnoy lingvistiki. 1982 [Problems of Structural Linguistics. 1982]. Moscow, Nauka Publ., pp. 5-23.

Arutyunova N.D., 1988. Tipy yazykovykh znacheniy. Ocenka. Sobytie. Fakt [Types of Linguistic Meanings. Assessment. Event. Fact]. Moscow, Nauka Publ. 341 p.

Barazgova E.S., 1997. Amerikanskaya sotsiologiya: Traditsii i sovremennost [American Sociology: Tradition and Modernity]. Yekaterinburg, Delovaya kniga Publ., Bishkek, Odissey Publ. $173 \mathrm{p}$.

Bartminskiy E., 2005. Yazykovoy obraz mira: ocherki po yetnolingvistike [The Language Image of the World: Essays on Ethnolinguistics]. Moscow, Indrik Publ. 527 p.

Berezovich E.L., 2007. Yazyk i traditsionnaya kultura: etnolingvisticheskie issledovaniya [Language and Traditional Culture: Ethno-Linguistic Research]. Moscow, Indrik Publ. 599 p.

Bogdanova L.I., 2017. Otsenki i tsennosti v zerkale slovarey russkogo yazyka [The Reflection of Evaluation and Values in Russian Language Dictionaries]. Vestnik RUDN. Seriya: Lingvistika [Russian Journal of Linguistics], vol. 21, no. 4, pp. 729-748.

Bogdanova L.I., 2018. Ocenochnye smysly v russko y grammatike [Evaluative Senses in Russian Grammar]. Vestnik RUDN. Seriya: Lingvistika [Russian Journal of Linguistics], vol. 22, no. 4, pp. 844-873.

Vezhbickaya A., 2001. Ponimanie kultury cherez posredstvo klyuchevyh slov [Understanding Cultures Through Their Key Words]. Moscow, Yazyki slavyanskoy kultury Publ. 288 p.

Vereshchagin E.M., Kostomarov V.G., 1990. Yazyk $i$ kultura. Lingvostranovedenie $v$ prepodavanii russkogo yazyka kak inostrannogo [Language and Culture: Linguistic and Cultural Studies in Teaching Russian as a Foreign Language]. Moscow, Russkiy yazyk Publ. 246 p.

Volf E.M., 1985. Funktsionalnaya semantika ocenki [Functional Semantics Evaluation]. Moscow, Nauka Publ. 228 p.

Gladkova A.N., 2010. Russkaya kulturnaya semantika: Emocii, tsennosti, zhiznennye ustanovki [Russian Cultural Semantics: Emotions, Values, Attitudes]. Moscow, Yazyki slavyanskikh kultur Publ. 295 p.

Zhivov V.M., 2009. Istoriya ponyatiy, istoriya kultury, istoriya obshchestva [History of Concepts, 
History of Culture, History of Society]. Ocherki istoricheskoy semantiki russkogo yazyka rannego Novogo vremeni [Essays of Russian Language Historical Semantics of Early Modern Times]. Moscow, Yazyki slavyanskikh kultur Publ., pp. 5-26.

Zaliznyak Anna A., Levontina I.B., Shmelyov A.D., 2012. Konstanty i peremennye russkoy yazykovoy kartiny mira [The Essential Ideas of the Russian Language World View]. Moscow, Yazyki slavyanskikh kultur Publ. 696 p.

Ivanova S.V., 2004. Lingvokulturologiya $i$ lingvokognitologiya: sopryazhenie paradigm [Cultural Linguistics and Cognitive Linguistics: Alignment of Paradigms]. Ufa, RIO BashGU. $152 \mathrm{p}$.

Karasik V.I., 2002. Yazyk socialnogo statusa [Language of Social Status]. Moscow, Gnozis Publ. 333 p.

Karasik V.I., 2005. Lingvokulturnyy tipazh «russkiy intelligent» [Linguacultural Type of the "Russian Intellectual"]. Aksiologicheskaya lingvistika: lingvokulturnye tipazhi: sb. nauch. tr. [Axiological Linguistics: Linguocultural Types. Collection of Scientific Works]. Volgograd, Paradigma Publ., pp. 25-61.

Kozlova L., 2018. Etnokulturnyy potentsial zalogovykh form i aktualizatsiya yego diskursa [The Ethnocultural Potential of Voice Forms and Its Discourse Actualization]. Vestnik RUDN. Seriya: Lingvistika [Russian Journal of Linguistics], vol. 22 , no. 4 , pp. 874-894.

Larina T.V., Ozyumenko V.I., 2017. Svoboda lichnosti kak konstituiruyushchiy komponent angliyskogo diskursa [Personal Freedom as a Constituent Component of English Discourse]. Izvestiya Yuzhnogo Federalnogo universiteta. Filologicheskie nauki [Proceedings of South Federal University. Philological Sciences], no. 2, pp. 160-172.

Leontovich O.A., 2005. Russkie $i$ amerikantsy: paradoksy mezhkulturnoy kommunikatsii [Russian and Americans; Paradoxes of Intercultural. Communication]. Moscow, Gnozis Publ. 344 p.

Lopatin V.V., 2007. Otsenka kak obyekt grammatiki [Assessment as an Object of Grammar]. Ivanova O.E., ed. Mnogogrannoe russkoe slovo: Izbrannye statyi po russkomu yazyku [Multifaceted Russian Word: Selected Articles on the Russian Language]. Moscow, Azbukovnik Publ., pp. 536-542.

Mamontov A.S., Cyedyendorzhiyn Ye., Boguslavskaya V.V., 2019. Lingvostranovedcheskiy uchebnyy slovar dlya mongolskih grazhdan: specifika predstavleniya materiala [Linguistic and Country Studies Learner's Dictionary for
Mongolian Citizens: Specifics of Presenting the Material]. Vestnik Volgogradskogo gosudarstvennogo universiteta. Seriya 2. Yazykoznanie [Science Journal of Volgograd State University. Linguistics], vol. 18, no. 1, pp. 74-85. DOI: https://doi.org/10.15688/ jvolsu2.2019.1.6.

MarkelovaT.V.,2007. Aksiologichnostkakimmanentnoe svoystvo gazetno-publitsisticheskogo teksta [Axiologiness as an Immanent Property of a Newspaper and Journalistic Text]. Yazyk $i$ stil sovremennykh SMI: mezhvuz. sb. nauch. tr. Vseros. konf., posvyashch. 80-letiyu prof. N.S. Valginoy [Language and Style of Modern Media. Interuniversity Collection of Scientific Works. All-Russian Conference Dedicated to the $80^{\text {th }}$ Anniversary of Professor N.S. Valgina]. Moscow, MGUP, pp. 231-238.

Maryanchik V.A., 2013. Aksiologichnost i otsenochnost media-politicheskogo teksta [Axiologiness and Evaluativeness of a Media-Political Text]. Moscow, Librokom Publ. 272 p.

Matveev P.E., 2006. Etika. Osnovy obshchey teorii morali [Ethics. Foundations of a General Theory of Morality]. Vladimir, Izd-vo Vladimirskogo gosudarstvennogo universiteta. $81 \mathrm{p}$

Salnikova Yu.A., 2014. Aksiologicheskie aspekty mediadiskursa [Axiological Aspects of Media Discourse]. Birobidzhan, Izdatelskiy tsentr FBGOU VPO «PGU im. Sholom-Aleykhema». $157 \mathrm{p}$.

Sinyachkin V.P., 2009. Formy sushchestvovaniya obshchechelovecheskikh tsennostey v russkoy kulture [Forms of the Universal Values Existence in Russian Culture]. Vestnik Chuvashskogo gosudarstvennogo pedagogicheskogo universiteta [I. Yakovlev Chuvash State Pedagogical University Bulletin], no. 10-2, pp. 273-288.

Sternin I.A., 2003. K razrabotke modeli kontrastivnogo opisaniya natsionalnogo kommunikativnogo povedeniya [To the Model Development of Contrastive Description of National Communicative Behavior]. Karasik V.I., Krasavskiy N.A., eds. Aksiologicheskaya problematika: problemy kommunikativnogo povedeniya: sb. nauch. tr. [Axiological Problems: Problems of Communicative Behavior. Collection of Scientific Works]. Volgograd, Peremena Publ., pp. 5-15.

Teliya V.N., 1996. Russkaya frazeologiya. Semanticheskiy, pragmaticheskiy $i$ lingvokulturologicheskiy aspekty [Russian Phraseology. Semantic, Pragmatic and Linguocultural Aspects]. Moscow, Yazyki russkoy kultury Publ. 288 p.

Ufimceva N.V., 2015. Yadro yazykovogo soznaniya kak otrazhenie sistemnosti obraza mira [The Core 
of a Language Consciousness as a Reflection of Image of the World Consistency]. Yazyk $v$ prostranstve rechevykh kultur. K 80-letiyu E.V. Goldina [Language in the Space of Speech Cultures. To the $80^{\text {th }}$ Anniversary of E.V. Goldin]. Moscow, Saratov, Nauka obrazovaniya Publ., pp. 335-342.

Teliya V.N., ed. Frazeologiya v kontekste kultury: sb. st. [Phraseology in the Context of Culture. Collection of Articles], 1999. Moscow, Yazyki russkoy kultury Publ. 333 p.

Tsyedyendorzhiyn Ye., 2015. Yazyk i kultura: osnovy natsionalno orientirovannoy leksikografii (s pozitsii nositelya mongolskogo yazyka) [Language and Culture: Basics of Nationally Oriented Lexicography (From the Perspective of a Native Speaker of the Mongolian Language)]. Moscow, Gosudarstvennyy IRYa im. A.S. Pushkina. 200 p.

Etnosemiometriya tsennostnykh smyslov [Ethnosemiometry of Value Meanings], 2008. Irkutsk, IGLU. 529 p.

Goddard C., Wierzbicka, A., eds., 2002. Meaning and Universal Grammar: Theory and Empirical Findings. In 2 Vols. Amsterdam, John Benjamins. Goddard C., Wierzbicka A., 2014. Words and Meanings: Lexical Semantics Across Domains,
Languages, and Cultures. Oxford, Oxford University Press. 316 p.

Kecskes I., 2014. Intercultural Pragmatics. Oxford, Oxford University Press. 277 p.

Kluckhohn F., Strodtbeck F.L., 1961. Variations in Value Orientations. Connecticut, Greenwood Press. 437 p.

Larina T.V., Ozyumenko V.I., Kurteš S., 2017. I-Identity vs We-Identity in Language and Discourse. AngloSlavonic Perspectives Lodz Papers in Pragmatics, vol. 13, iss. 1, pp. 109-128.

Leech G., 2014. The Pragmatics of Politeness. Oxford, Oxford University Press. 369 p.

Wierzbicka A., 2003. Cross-Cultural Pragmatics. $2^{\text {nd }}$ ed. Berlin, New York, Mouton de Gruyter. 502 p.

\section{SOURCES AND DICTIONARIES}

Kuznetsov S.A. Novyy bolshoy tolkovyy slovar russkogo yazyka [A New Large Explanatory Russian Dictionary]. Saint Petersburg, Norint Publ., 2000. 1536 p.

Karaulov Yu.N., ed. Russkiy associativnyy slovar. V 2 t. [Russian Associative Dictionary. In 2 Vols.]. Moscow, AST Publ., Astrel Publ., 2002. 2 vols.

Hoang Phe. Tu dien Tieng Viet [Vietnamese Dictionary]. Vien Ngon ngu hoc, NXB Da Nang, 2003.1222 tr. (In Vietnamese).

\section{Information About the Authors}

Aleksandr S. Mamontov, Doctor of Sciences (Philology), Professor, Department of Russian Arts and Intercultural Communication, Pushkin State Russian Language Institute, Akademika Volgina St, 6, 117485 Moscow, Russia, as-mamontov2@yandex.ru, https://orcid.org/0000-0002-6703-637X

Vera V. Boguslavskaya, Doctor of Sciences (Philology), Professor, Department of Russian Arts and Intercultural Communication, Pushkin State Russian Language Institute, Akademika Volgina St, 6, 117485 Moscow, Russia, boguslavskaya@gmail.com, https://orcid.org/0000-0003-4118-382X

Ekaterina A. Budnik, Candidate of Sciences (Pedagogy), Associate Professor, Department of Russian Arts and Intercultural Communication, Pushkin State Russian Language Institute, Akademika Volgina St, 6, 117485 Moscow, Russia, ebudnik11@gmail.com, https://orcid.org/0000-0001-5055-8908

Albertina G. Ratnikova, Candidate of Sciences (Pedagogy), Lecturer, Department of Russian as a Foreign Language, Pushkin State Russian Language Institute, Akademika Volgina St, 6, 117485 Moscow, Russia, porijoki@nextmail.ru, https://orcid.org/0000-0003-3480-4798

Trinh Thi Kim Ngoc, Doctor of Sciences (Philology), Professor, Scientific Consultant on Cultural and Social Issues, Institute of Human Sciences, Vietnam Academy of Social Sciences, Kim Ma Thuong St,9a,100118 Hanoi, Vietnam,ngocha098@gmail.com

\section{Информация об авторах}

Александр Степанович Мамонтов, доктор филологических наук, профессор кафедры русской словесности и межкультурной коммуникации, Государственный институт русского языка им. А.С. Пушкина, ул. Академика Волгина, 6, 117485 г. Москва, Россия, as-mamontov2@yandex.ru, https://orcid.org/0000-0002-6703-637X 
Аксиологическая лингвистика и национально ориентированная лексикография: опыт взаимодействия

Вера Васильевна Богуславская, доктор филологических наук, профессор кафедры русской словесности и межкультурной коммуникации, Государственный институт русского языка им. А.С. Пушкина, ул. Академика Волгина, 6, 117485 г. Москва, Россия, boguslavskaya@gmail.com, https://orcid.org/0000-0003-4118-382X

Екатерина Александровна Будник, кандидат педагогических наук, доцент кафедры русской словесности и межкультурной коммуникации, Государственный институт русского языка им. А.С. Пушкина, ул. Академика Волгина, 6, 117485 г. Москва, Россия, ebudnik11@gmail.com, https://orcid.org/0000-0001-5055-8908

Альбертина Германовна Ратникова, кандидат педагогических наук, педагог кафедры русского языка как иностранного, Государственный институт русского языка им. А.С. Пушкина, ул. Академика Волгина, 6, 117485 г. Москва, Россия, porijoki@nextmail.ru, https://orcid.org/0000-0003-3480-4798

Чинь Тхи Ким Нгок, доктор филологических наук, профессор, научный консультант по культурным и социальным вопросам, Институт человековедения, Вьетнамская академия общественных наук, ул. Ким Ма Тхыонг, 9а, 100118 г. Ханой, Вьетнам, ngocha098@gmail.com 